\title{
Effects of magnetic fields on Fe-Si composite electrodeposition
}

\author{
Qiong Long, Yun-bo Zhong, Huai Wang, Tian-xiang Zheng, Jun-feng Zhou, and Zhong-ming Ren
}

Shanghai Key Laboratory of Modern Metallurgy and Material Processing, Shanghai University, Shanghai 200072, China

(Received: 26 March 2014; revised: 15 June 2014; accepted: 16 June 2014)

\begin{abstract}
Coatings containing Fe-Si particles were electrodeposited on 3.0wt $\%$ Si steel sheets under magnetic fields. The effects of magnetic flux density (MFD), electrode arrangement and current density on the surface morphology, the silicon content in the coatings and the cathode current efficiency were investigated. When a magnetic field was applied parallel to the current and when the MFD was less than 0.5 $\mathrm{T}$, numerous needle-like structures appeared on the coating surface. With increasing MFD, the needle-like structures weakened and were transformed into dome-shaped structures. Meanwhile, compared to results obtained in the absence of a magnetic field, the silicon content in the coatings significantly increased as the MFD was increased for all of the samples obtained using a vertical electrode system. However, in the case of an aclinic electrode system, the silicon content decreased. Furthermore, the cathode current efficiency was considerably diminished when a magnetic field was applied. A possible mechanism for these phenomena was discussed.
\end{abstract}

Keywords: composite coatings; electrodeposition; silicon steel; magnetic field; surface morphology; silicon content; magnetohydrodynamics

\section{Introduction}

Silicon steel containing $6.5 \mathrm{wt} \%$ Si has attracted considerable interest because of its high permeability, high saturation magnetization, and nearly zero magnetostriction [1-4]. However, Si steel sheets with silicon contents greater than $4.0 \mathrm{wt} \%$ are very difficult to produce using traditional rolling processes because of their poor elongation properties. Recently, a new approach has been reported for preparing $6.5 \mathrm{wt} \%$ silicon steel sheets with $\mathrm{Fe}-\mathrm{Si}$ composite coatings, where an electrodeposited composite of iron with powdered silicon or ferrosilicon is processed into $6.5 \mathrm{wt} \% \mathrm{Si}$ steel sheets via heat treatment at high temperature [5-6]. However, how to increase the particle content in the coatings during electrodeposition is still the key point.

In the development of a new controllable method, researchers have attempted to use magnetic fields during electrochemistry processes [7-10]. The magnetohydrodynamic (MHD) effect induced by interaction between the magnetic field and the current is generally accepted to substantially enhance mass transport. Many researchers [11-13] have reported that the application of a magnetic field can signifi- cantly facilitate the incorporation of applied particles into the coatings. Yamada and Asai [14-15] observed that micron-grade $\mathrm{Al}_{2} \mathrm{O}_{3}$ particles distributed in a $\mathrm{Ni}$ matrix in a honeycomb pattern when a parallel magnetic field was superimposed on them. Moreover, the magnetic field gradient force is considered to be another factor affecting the electrodeposition process [16-17]. Peipmann et al. [18] electroplated nickel with co-deposited $\mathrm{Al}_{2} \mathrm{O}_{3}$ particles by electroless deposition of a thin nickel layer under magnetic fields and observed that the magnetized particles preferred to move to the nickel electrode surface under the field gradient force. At the same time, upward natural convection also can affect the deposition process [19]. Zhou et al. [20] electroplated iron with nano-Si particles in a vertical electrode system under a parallel magnetic field and observed that the Si particles distributed on the coating surface in a striped pattern under the interaction of the MHD effect and natural convection. Unfortunately, the literature contains few accounts related to electrodeposition of iron with silicon under a magnetic field. Thus, we wondered about the effect of applying a magnetic field during electrodeposition of iron with Fe-Si particles.

In this paper, $\mathrm{Fe}-\mathrm{Si}$ composite electrodeposition was 
conducted in a static magnetic field with a magnetic flux density (MFD) ranging from 0 to $1 \mathrm{~T}$. The effects of the magnetic field on the surface morphology and the particle content in the coatings are discussed.

\section{Experimental}

Fe-Si alloy powders (including $\mathrm{Fe}-30 \mathrm{wt} \% \mathrm{Si}$, $\mathrm{Fe}-50 \mathrm{wt} \% \mathrm{Si}$, and $\mathrm{Fe}-70 \mathrm{wt} \% \mathrm{Si}$ powders) with an average size of $2.5 \mu \mathrm{m}$ were added to the electrolyte to prepare $\mathrm{Fe}-\mathrm{Si}$ composite coatings; the difference in diameter among these particles was negligible. First, analytical-grade iron and silicon powders were mixed in the proportions of $30 \mathrm{wt} \% \mathrm{Si}, 50 \mathrm{wt} \% \mathrm{Si}$, and $70 \mathrm{wt} \% \mathrm{Si}$ and were melted into $\mathrm{Fe}-\mathrm{Si}$ alloy ingots at high temperature under high vacuum. The $\mathrm{Fe}-\mathrm{Si}$ alloy ingots were processed into powders by ball milling using wolfram carbide balls and alcohol. The composition of the bath solution and the electrodeposition conditions are shown in Tables 1 and 2. All of the experiment reagents were of analytical grade. The $\mathrm{pH}$ value was adjusted to 1.5 with $\mathrm{H}_{2} \mathrm{SO}_{4}$. $\mathrm{Cl}^{-}$not only prevented passivation of the pure iron anode but also enhanced polarization and modified the layers; hexadecyl trimethyl ammonium bromide (HTAB) was used as a dispersing agent to prevent agglomeration of Fe-Si particles.

Table 1. Composition of the bath solution for Fe-Si composite electrodeposition

\begin{tabular}{lc}
\hline \multicolumn{1}{c}{ Component } & Concentration $/\left(\mathrm{g} \cdot \mathrm{L}^{-1}\right)$ \\
\hline $\mathrm{NH}_{4} \cdot \mathrm{Cl}$ & 23 \\
$\mathrm{FeSO}_{4} \cdot 7 \mathrm{H}_{2} \mathrm{O}$ & 250 \\
$\mathrm{FeCl}_{2} \cdot 4 \mathrm{H}_{2} \mathrm{O}$ & 30 \\
$\mathrm{Hexadecyl}$ trimethyl ammonium & 0.2 \\
bromide $(\mathrm{HTAB})$ & \\
\hline
\end{tabular}

Table 2. Deposition conditions in magnetic field

\begin{tabular}{lc}
\hline \multicolumn{1}{c}{ Deposition conditions } & Value \\
\hline Average particle size $/ \mu \mathrm{m}$ & 2.5 \\
Current density, $J_{0} /\left(\mathrm{A} \cdot \mathrm{dm}^{-2}\right)$ & $1-4$ \\
$\mathrm{pH}$ value & 1.5 \\
Temperature $/{ }^{\circ} \mathrm{C}$ & 30 \\
Stirring speed $/\left(\mathrm{r} \cdot \mathrm{min}^{-1}\right)$ & 60 \\
Magnetic flux density, $B / \mathrm{T}$ & $0-1$ \\
Electroplating time $/ \mathrm{min}$ & 120 \\
Concentration of particles $/\left(\mathrm{g} \cdot \mathrm{L}^{-1}\right)$ & 10 \\
\hline
\end{tabular}

During the electrodeposition process, an external magnetic field was applied. The schematic diagram of the mag- neto-electrolysis setup is shown in Fig. 1. The direction of the magnetic field was horizontal. Two systems of electrodes arranged in aclinic and vertical directions were used to study the effects of the magnetic field. When the vertical electrode system was used, the magnetic field was parallel ( $\boldsymbol{B} / / \boldsymbol{J})$ or perpendicular $(\boldsymbol{B} \perp \boldsymbol{J})$ to the current, whereas it was perpendicular to the current when the aclinic electrode system was used. At the same time, to ensure that particles were uniformly suspended in the electrolyte, the plating solution was mechanically stirred. The cathode was a $3.0 \mathrm{wt} \%$ Si steel sheet $(20 \mathrm{~mm} \times 30 \mathrm{~mm} \times 0.25 \mathrm{~mm})$, and the anode was a pure iron sheet $(20 \mathrm{~mm} \times 30 \mathrm{~mm} \times 0.25 \mathrm{~mm}, \mathrm{Fe}$ 99.99\%). The distance between the cathode and anode was $20 \mathrm{~mm}$. Before electrodeposition, the electrolyte was agitated with pure argon bubbles to decrease the oxygen content in the electrolyte. After each experiment, the obtained sample was first cleaned by ultrasonic $(100 \mathrm{~W}, 5.7 \mathrm{MHz})$ treatment for $2 \mathrm{~min}$ to remove the adsorbed particles and was then cleaned with alcohol and dried under a stream of cold air.

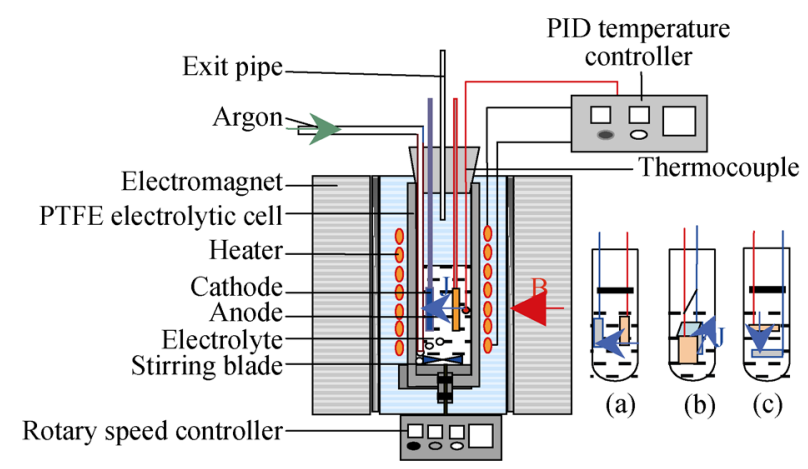

Fig. 1. Diagram of the experimental equipment: (a) vertical electrode system $(B / / J)$; (b) vertical electrode system $(B \perp J)$; (c) aclinic electrode system $(B \perp J)$.

Stereoscopic microscopy (VHX-2000, Keyence) and scanning electron microscopy (SEM, VEGA 3 SBH-Easyprobe) with energy-dispersive X-ray spectroscopy (EDX, BRUKER) were used to study the surface morphology and the silicon content of the coatings. Back-scattered electron imaging was used to evaluate the distribution of particles in the cross-sections.

\section{Results and discussion}

\subsection{Composite electrodeposition in a parallel magnetic field $(B / / J)$}

The surface morphology of the $\mathrm{Fe}-\mathrm{Si}$ coatings obtained at a current density of $2 \mathrm{~A} \cdot \mathrm{dm}^{-2}$ in a parallel magnetic field using the vertical electrode system is shown in Fig. 2. 

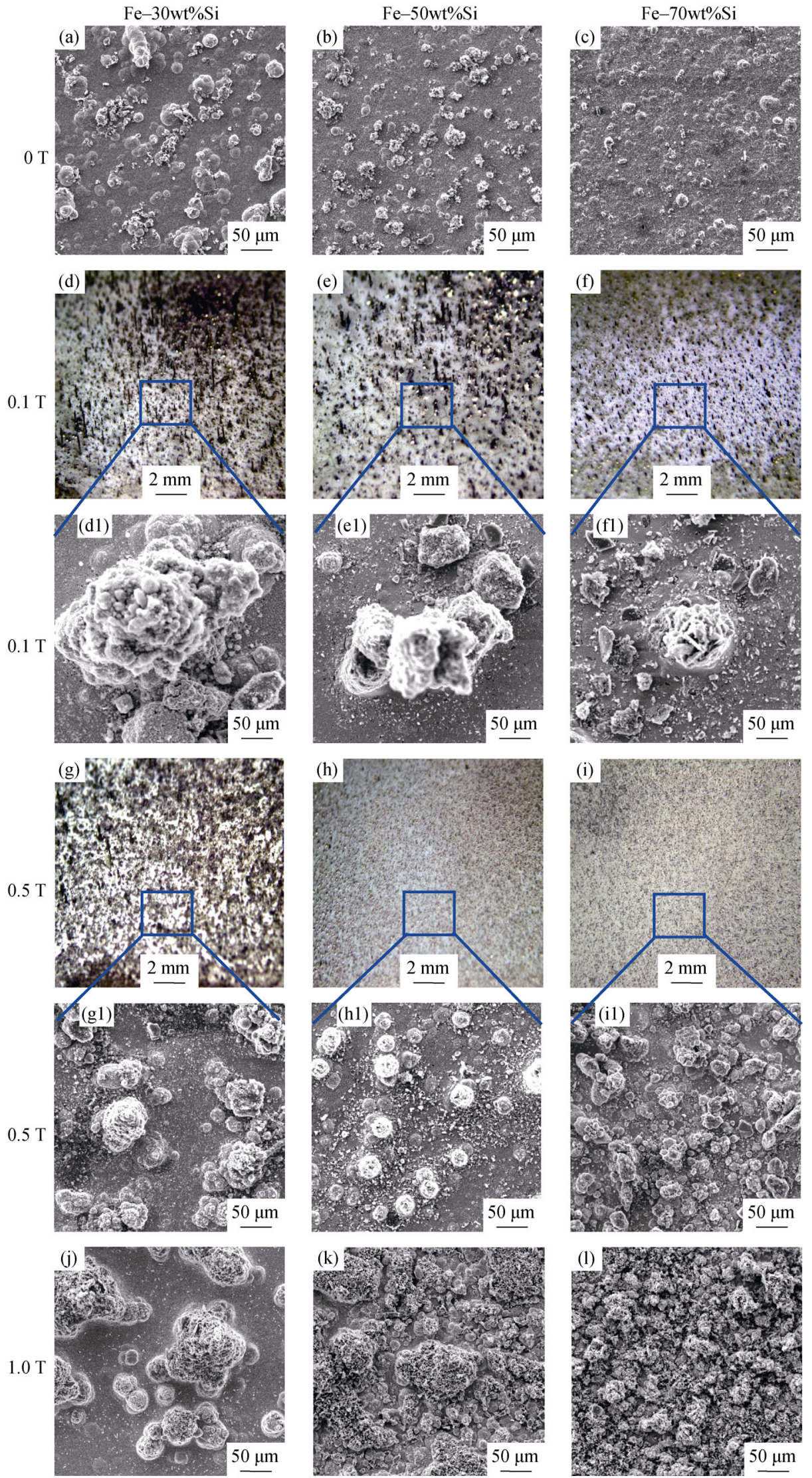

Fig. 2. SEM micrographs of the surface morphology of Fe-Si particles coated at $2 \mathrm{~A}^{\circ} \mathrm{dm}^{-2}$ in $0 \mathrm{~T}(\mathrm{a}-\mathrm{c}), 0.1 \mathrm{~T}(\mathrm{~d} 1-\mathrm{f} 1), 0.5 \mathrm{~T}(\mathrm{~g} 1-\mathrm{i} 1)$, and $1 \mathrm{~T}(\mathrm{j}-\mathrm{I})$ fields. Images $(\mathrm{d}-\mathrm{i})$ were imaged using a stereoscopic microscope. 
Compared to the smooth surface morphology in the absence of a magnetic field (Figs. 2(a)-2(c)), numerous needle-like structures appeared on the Fe-Si coating surface at $0.1 \mathrm{~T}$ (Figs. 2(d)-2(f) and 2(d1)-2(f1)). With increasing silicon content in the applied particles, the number and length of the needle-like structures on the coating surface significantly decreased. The length for the $30 \mathrm{wt} \%$ Si particles reached 4 $\mathrm{mm}$, whereas that for the $70 \mathrm{wt} \% \mathrm{Si}$ particles was only 1 $\mathrm{mm}$.

With increasing MFD, the needle-like protrusions were diminished, and only small dot protrusions were observed when the MFD reached $0.5 \mathrm{~T}$ (Figs. 2(g)-2(i) and 2(g1)-2(i1)). When the MFD was increased further, the needle-like protrusions disappeared at the macroscale and were transformed into microdome-shaped structures under a 1-T magnetic field; in addition, the diameter of the protru- sions decreased with increasing silicon content in the $\mathrm{Fe}-\mathrm{Si}$ particles (Figs. 2(j)-2(1)).

Fig. 3 shows the cross-sections of the samples obtained in the absence and presence of a 1-T magnetic field. The figure indicates that the Fe-Si particles incorporated into the coatings were distributed in the central area of the protuberances after a 1-T magnetic field was superimposed (Figs. 3(d)-3(f)) and that the number of incorporated particles increased significantly compared to that in the absence of a magnetic field. This result is in agreement with the surface morphology of the coatings. At the same time, the coating thickness for all of samples prepared in the absence of an applied magnetic field was approximately $45 \mu \mathrm{m}$, but after imposing a 1-T applied magnetic field, the obtained coating thickness markedly increased by at least $5 \mu \mathrm{m}$, where some microcracks appeared between the coating and the substrate.
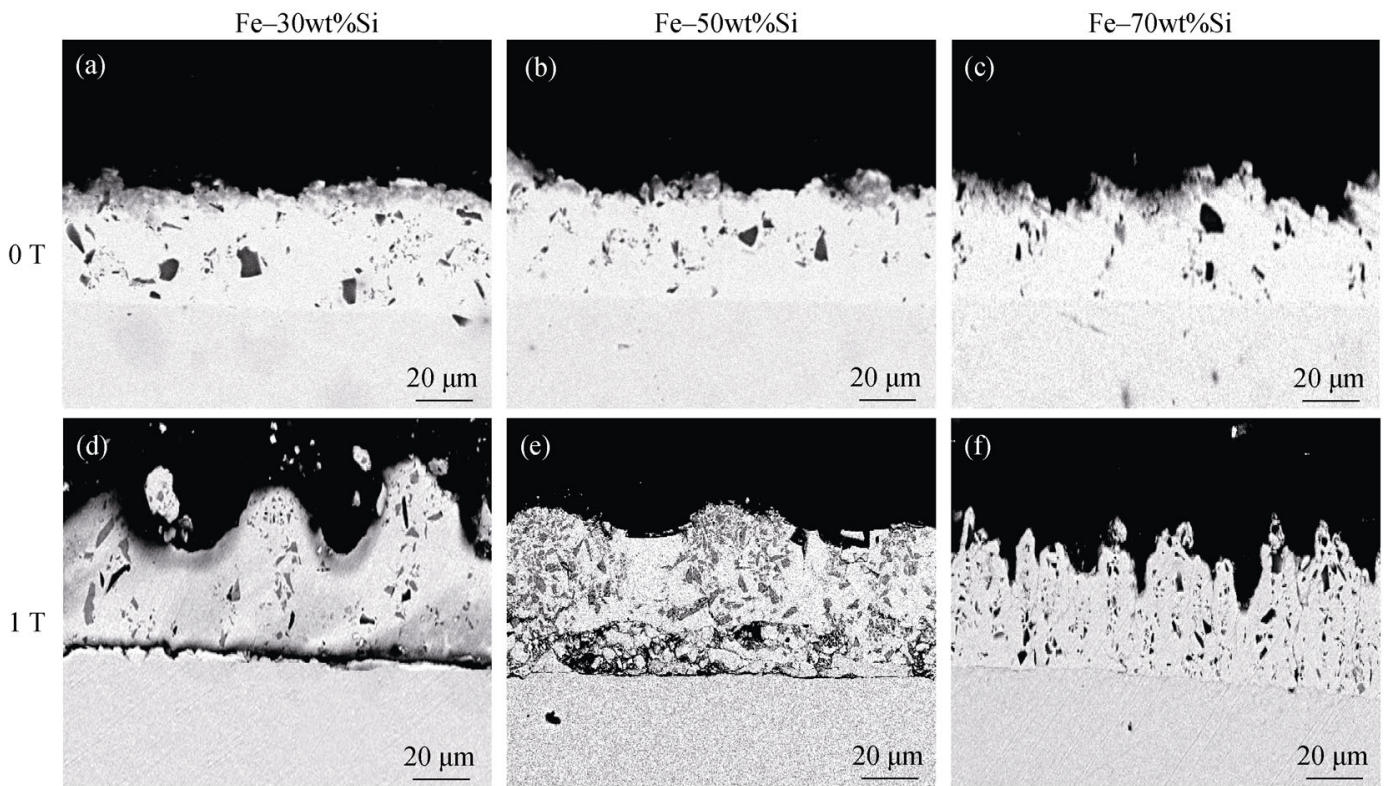

Fig. 3. Micrographs of the cross-sections of Fe-Si coatings deposited in the absence (a-c) and presence of a 1-T (d-f) magnetic field.

Fig. 4 shows that the silicon content of the coatings for the $\mathrm{Fe}-50 \mathrm{wt} \% \mathrm{Si}$ and the $\mathrm{Fe}-70 \mathrm{wt} \% \mathrm{Si}$ particles significantly increased with increasing MFD and that a silicon content of approximately $20 \mathrm{wt} \%$ could be obtained with $\mathrm{Fe}-70 \% \mathrm{Si}$ particles under a 1-T magnetic field. However, in the case of $\mathrm{Fe}-30 \mathrm{wt} \% \mathrm{Si}$ particles, the silicon content tended to slightly decrease when the MFD was greater than $0.1 \mathrm{~T}$.

The aforementioned experimental results imply that the parallel magnetic field substantially influenced the electrodeposition process of iron-containing magnetic microparticles. Normally, the magnetic field in the air gap of an electromagnet is nearly homogeneous, which means that the magnetic field gradient is relatively small. However, the cathode was a $3-w t \%$ silicon steel sheet, which is a soft

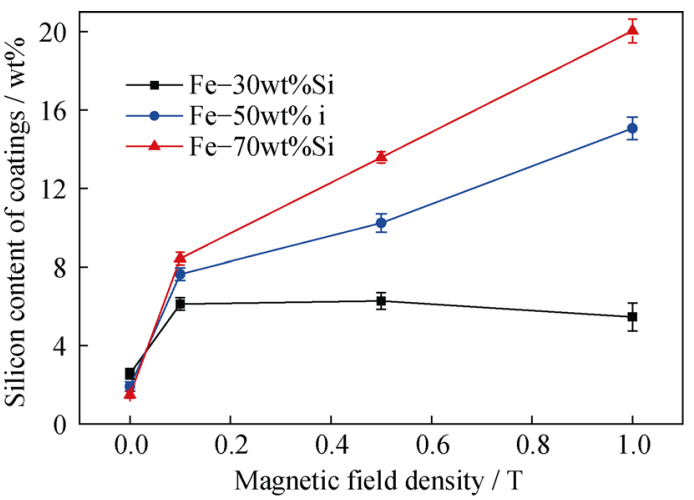

Fig. 4. Silicon content of Fe-Si coatings deposited using the vertical electrode system at $2 \mathrm{~A} \cdot \mathrm{dm}^{-2}$ in a parallel magnetic field. 
magnetic material. If it is placed in a magnetic field, an inhomogeneous magnetic field should be induced on the electrode surface. The magnetic flux is concentrated into the electrode surface, which induces a strong magnetic gradient in the adherent area of the iron electrodes. Thus, the role of the field gradient force $\boldsymbol{F}_{\nabla B}$ is significant, and its effect should be considered in the electrodeposition process under an inhomogeneous magnetic field. According to Peipmann et al. [18], a field gradient force $\left(\boldsymbol{F}_{\nabla B}\right)$ will be induced on the magnetic particles when a gradient of the magnetic field $(\nabla \boldsymbol{B})$ exists:

$$
\boldsymbol{F}_{\nabla B}=\chi V \boldsymbol{B} \cdot \nabla \boldsymbol{B} / \mu_{0}
$$

where $\mu_{0}=4 \pi \times 10^{-7} \mathrm{~V} \cdot \mathrm{s} /(\mathrm{A} \cdot \mathrm{m})$ denotes the vacuum permeability, $\chi$ is the magnetic susceptibility of particles, $\boldsymbol{B}$ is the MFD, and $V$ is the volume of the particle. Eq. (1) reveals that $\boldsymbol{F}_{\nabla B}$ will increase linearly with increasing $\chi$ or $\nabla \boldsymbol{B}$. Therefore, the magnetic particles suspended in the electrolyte experience a strong $\boldsymbol{F}_{\nabla B}$, which promotes the movement of magnetic particles toward the electrode surface. In the case of the cathode, the accumulation of the particles can strengthen the incorporation process and then result in an increase in particle content of the coatings.

Fig. 5 shows the hysteresis loops of the Fe-Si particles. All of the Fe-Si particles exhibit ferromagnetic properties, and the Fe-30wt $\%$ Si particles have a much higher suscepti-

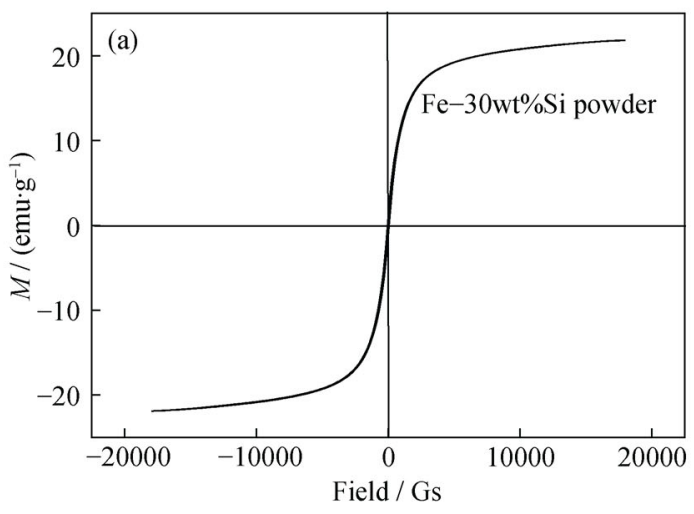

Fig. 5. Hysteresis loops of $\mathrm{Fe}-30 \mathrm{wt} \% \mathrm{Si}$ particles

However, needle-like structures on the coating surface disappeared at the macroscale when the magnetic field reached $1 \mathrm{~T}$. In this case, the $\boldsymbol{F}_{\nabla B}$ is much larger than that in a 0.1-T field, and the needle-like structures should not disappear. Obviously, another factor dominates the shape of the coatings and the co-deposition process of the Fe-Si particles. According to Ampere's law, the Lorentz force should not be generated when the magnetic field is parallel to the current. However, as the needle-like structure gradually forms on the cathode surface, the current is distorted in front bility than the other types of particles. Therefore, the Fe-Si particles suspended in the electrolyte will move preferentially toward the locations with a higher $\nabla \boldsymbol{B}$, which results in a large number of needle-like protrusions forming along the direction of the magnetic field on the cathode surface. At the same time, according to Eq. (1), the $\boldsymbol{F}_{\nabla B}$ in the vicinity of electrodes in the case of $\mathrm{Fe}-30 \mathrm{wt} \% \mathrm{Si}$ particles was much larger than those in the cases of the $\mathrm{Fe}-50 \mathrm{wt} \% \mathrm{Si}$ and $\mathrm{Fe}-70 \mathrm{wt} \% \mathrm{Si}$ particles. Therefore, for the samples obtained under a $0.1 \mathrm{~T}$ magnetic field, the number and the length of the needle-like structures on the surface of the coatings were much greater than those of the $\mathrm{Fe}-50 \mathrm{wt} \% \mathrm{Si}$ and $\mathrm{Fe}-70 \mathrm{wt} \% \mathrm{Si}$ particles. In the case of the diamagnetic Si particles, the surface of the composite coatings did not exhibit needle-like structures [21]. Meanwhile, some Fe-30wt $\% \mathrm{Si}$ particles exhibited a strong tendency to move toward the anode surface, which can lead to a massive loss of particles into solution and therefore result in a slight decrease in silicon content of the coatings when the MFD is greater than $0.1 \mathrm{~T}$. The $\boldsymbol{F}_{\nabla B}$ for the $\mathrm{Fe}-50 \mathrm{wt} \% \mathrm{Si}$ and $\mathrm{Fe}-70 \mathrm{wt} \% \mathrm{Si}$ particles is relatively small and may not be sufficiently large to result in a considerable loss of $\mathrm{Fe}-\mathrm{Si}$ particles on the anode surface, which is helpful for the accumulation of the $\mathrm{Fe}-50 \mathrm{wt} \% \mathrm{Si}$ and $\mathrm{Fe}-70 \mathrm{wt} \% \mathrm{Si}$ particles on the cathode surface and leads to increased silicon content in the coatings.

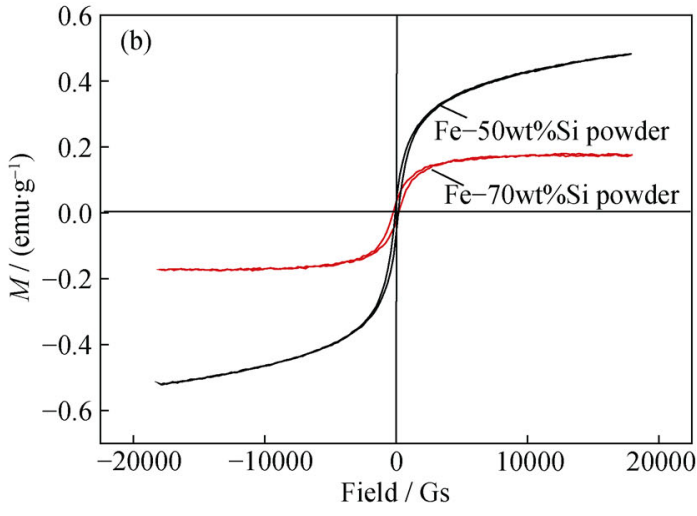

(a) and $\mathrm{Fe}-50 \mathrm{wt} \% \mathrm{Si}$ and $\mathrm{Fe}-70 \mathrm{wt} \% \mathrm{Si}$ particles (b).

of the needle-like protrusions (Fig. 6(a)), which results in a current component that is perpendicular to the magnetic field [21-22]. Then, a Lorentz force $\left(\boldsymbol{F}_{\mathrm{L}}\right)$ will be induced by the interaction of an imposed magnetic field $(\boldsymbol{B})$ and a distorted electrolytic current $\left(\boldsymbol{J}_{\mathrm{r}}\right)$; this force can be expressed as $\boldsymbol{F}_{\mathrm{L}}=\boldsymbol{J}_{\mathrm{r}} \times \boldsymbol{B}$

As a result, a clockwise eddy of the electrolyte will be generated in front of the needle-like protrusion (Figs. 6(b) and 6(c)). With increasing MFD, the eddy becomes more intense, and a scouring effect in front of the needle-like 
structures is induced; this scouring effect can break down or constrain the growth of the needle-like structures. Meanwhile, compared with other types of particles, the needle-like protrusions of $\mathrm{Fe}-30 \mathrm{wt} \% \mathrm{Si}$ particles had greater MFD at the tips of the protrusions due to their higher susceptibility, which can further increase the MHD effect. Thus, only dome-shaped structures were observed on the coating surface deposited under a 1-T magnetic field. In the cases of $\mathrm{Fe}-50 \mathrm{wt} \% \mathrm{Si}$ and $\mathrm{Fe}-70 \mathrm{wt} \% \mathrm{Si}$ particles, the intensity of the scouring flow was comparably smaller than that of the
$\mathrm{Fe}-30 \mathrm{wt} \% \mathrm{Si}$ particles under a magnetic field that was equal to or greater than $0.5 \mathrm{~T}$ because of their lower susceptibility. As a result, the diameter of the dome-shaped protrusions decreased with increasing silicon content in the particles. Furthermore, the intensity of the scouring flow in the center of the dome-shaped structures was relatively low; the Fe-Si particles should therefore migrate preferentially toward the middle regions of the protrusions under the interaction of the centrifugal force and the $\boldsymbol{F}_{\nabla B}$ can be engulfed by the growing metal.
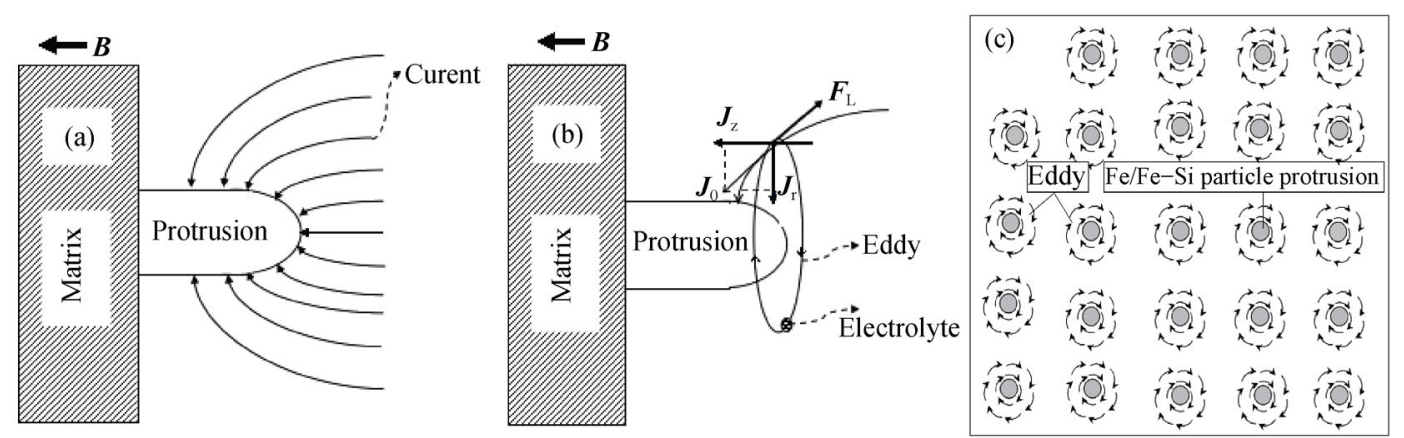

Fig. 6. Micro-schematic view illustrating the electrolytic current distributions in front of the needle-like protrusions (a), the formation of clockwise micro-flow (b), and many eddies formed on the cathode surface (c).

Long et al. and Wang et al. [21-22] observed that the micro-MHD effect can promote the incorporation of pure $\mathrm{Si}$ particles into the coatings in the presence of a weak parallel magnetic field; however, they also observed that, when a relatively strong magnetic field was superimposed, a scouring action was induced by the micro-MHD effect, which can retard the incorporation of particles. Fig. 7 shows the silicon content of the coatings obtained under a current density of 1-4 A $\cdot \mathrm{dm}^{-2}$ and under a 1-T magnetic field. In this case, the $\nabla \boldsymbol{B}$ should remain constant. According to Eq. (2), the MHD effect induced by the Lorentz force increased linearly with increasing current density. As shown in Fig. 7, the silicon content of the coatings for three types of $\mathrm{Fe}-\mathrm{Si}$ particles first increased and then decreased with increasing current density, exhibiting a maximum when the current density was $2 \mathrm{~A} \cdot \mathrm{dm}^{-2}$. Therefore, we deduced that an appropriate intensity of the MHD effect is another important factor for increasing the silicon content of the coatings. Furthermore, the silicon content of the $\mathrm{Fe}-50 \mathrm{wt} \% \mathrm{Si}$ and $\mathrm{Fe}-70 \mathrm{wt} \% \mathrm{Si}$ particles was much higher than that in the $\mathrm{Fe}-30 \mathrm{wt} \% \mathrm{Si}$ particles, which also can lead to an increase in silicon content of the coatings.

\subsection{Composite electrodeposition in a perpendicular magnetic field $(B \perp J)$}

3.2.1. Experimental results obtained using the vertical electrode system

Compared to the relatively smooth morphology obtained in the absence of a magnetic field (Figs. 2(a)-2(c)), the coating surface became coarse after we imposed a perpendicular magnetic field (Fig. 8); however, no needle-like structures appeared on the coating surface. Furthermore, the silicon content of the coatings significantly increased (Fig. 9). In the case of the $\mathrm{Fe}-30 \mathrm{wt} \% \mathrm{Si}$ particles, the silicon content of the coatings reached a maximum at a 0.1-T MFD and then decreased as the MFD was increased further; in contrast, the silicon content increased with increasing MFD in the cases of the $\mathrm{Fe}-50 \mathrm{wt} \% \mathrm{Si}$ and $\mathrm{Fe}-70 \mathrm{wt} \% \mathrm{Si}$ particles. The coatings with silicon contents greater than $9.0 \mathrm{wt} \% \mathrm{Si}$ were obtained when the MFD reached $1 \mathrm{~T}$.

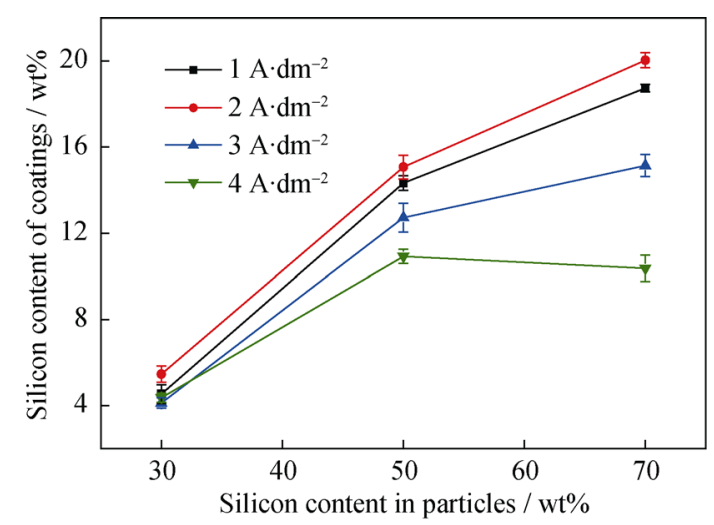

Fig. 7. Relationship between the silicon content of the coatings and the current density under a 1-T parallel magnetic field. 

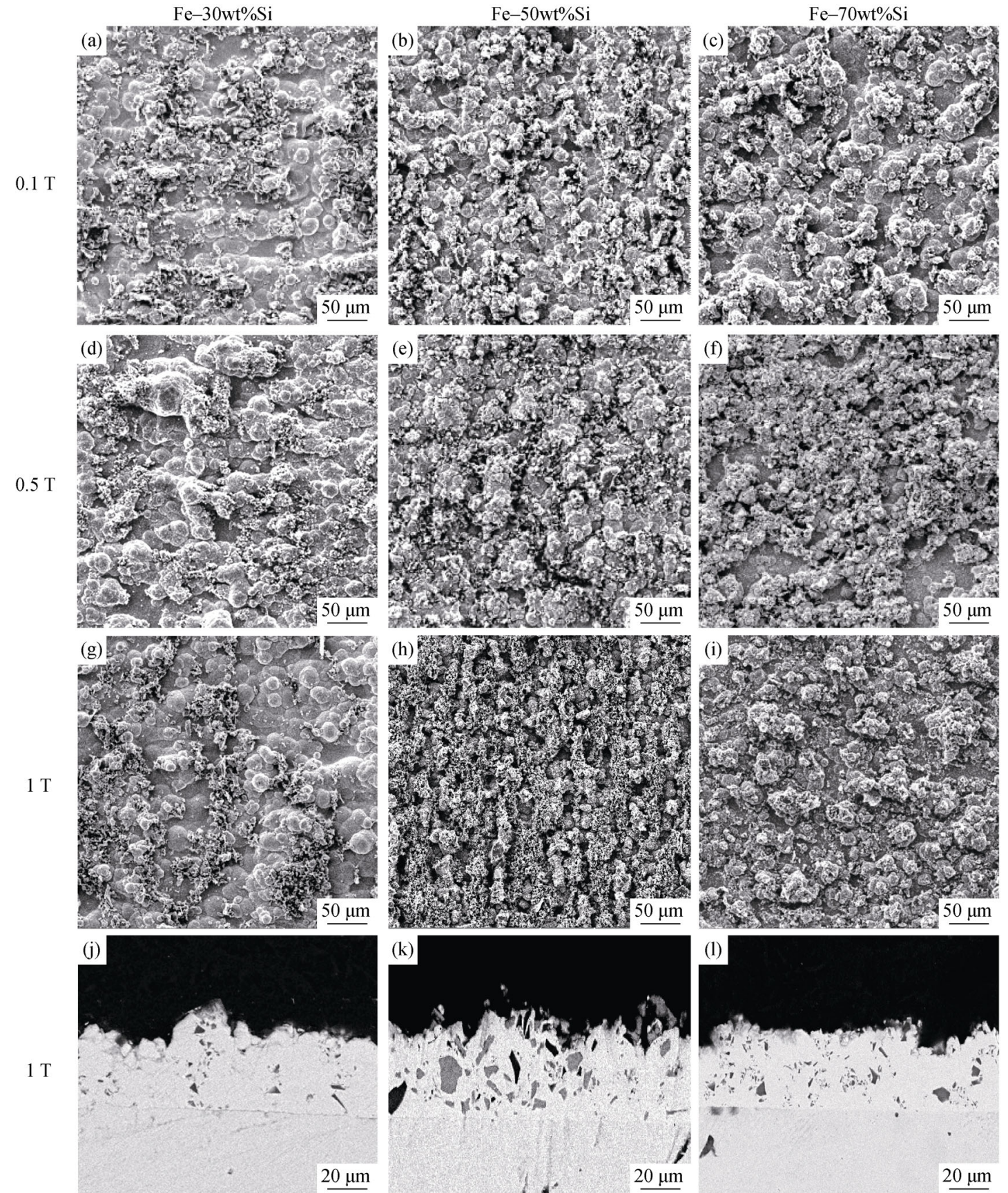

Fig. 8. SEM micrographs of the surface morphology of the composite coatings (a-i) when using the vertical electrode system in a perpendicular magnetic field at a current density of $2 \mathrm{~A} \cdot \mathrm{dm}^{-2}$; images $(\mathrm{j}-\mathrm{l})$ show the cross-sections under a 1-T magnetic field.

\subsubsection{Experimental results for the aclinic electrode system}

Fig. 10 shows the surface morphology of the coatings and the corresponding cross-sections obtained at a current density of $2 \mathrm{~A} \cdot \mathrm{dm}^{-2}$ in the absence and presence of a 1-T magnetic field in the aclinic electrode system. As evident in Fig. 10, the surface morphology of the coatings coarsened. At the same time, the coating thickness for all of the samples obtained in the absence of a magnetic field was approximately $50 \mu \mathrm{m}$; however, the thickness markedly decreased by at least $5 \mu \mathrm{m}$ when a 1-T magnetic field was applied. Furthermore, with increasing MFD, the silicon content of the coatings significantly decreased for all types of $\mathrm{Fe}-\mathrm{Si}$ particles (Fig. 11). However, the Fe-70wt\%Si particles exhibited the largest fluctuation and the silicon content of the coatings decreased from $35.22 \mathrm{wt} \%$ in the absence of a magnetic field to $22.85 \mathrm{wt} \%$ in the presence of a $1-\mathrm{T}$ magnetic field; in contrast, the silicon content of the coatings in the case of the $\mathrm{Fe}-30 \mathrm{wt} \% \mathrm{Si}$ particles changed only $2.33 \mathrm{wt} \%$. 


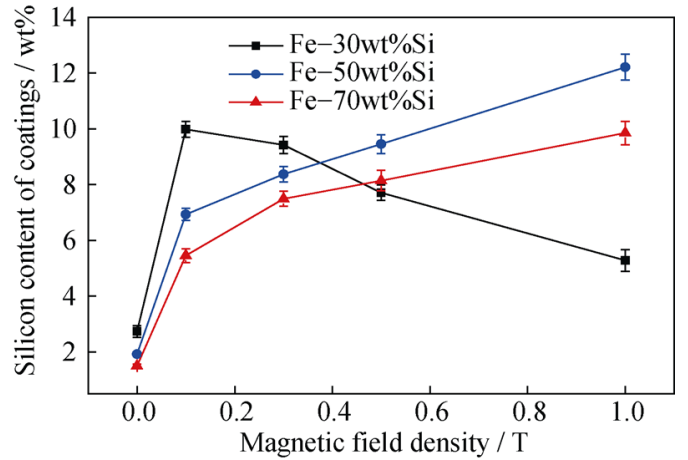

Fig. 9. Silicon content of the coatings for the vertical electrode system at a current density of $2 \mathbf{A \cdot d m ^ { - 2 }}$ in a perpendicular magnetic field.
3.2.3. Effects of current density on the silicon content of the coatings in a perpendicular magnetic field

Fig. 12 shows the silicon content of the coatings deposited in the absence and presence of a 1-T magnetic field under different current densities. The figure demonstrates that the silicon content of the coatings for all types of Fe-Si particles in the vertical electrode system first increased and then decreased with increasing current density, reaching a maximum at $2 \mathrm{~A} \cdot \mathrm{dm}^{-2}$ both in the absence and presence of a 1-T magnetic field. Conversely, the silicon content decreased linearly with increasing current density when the aclinic electrode system was used.
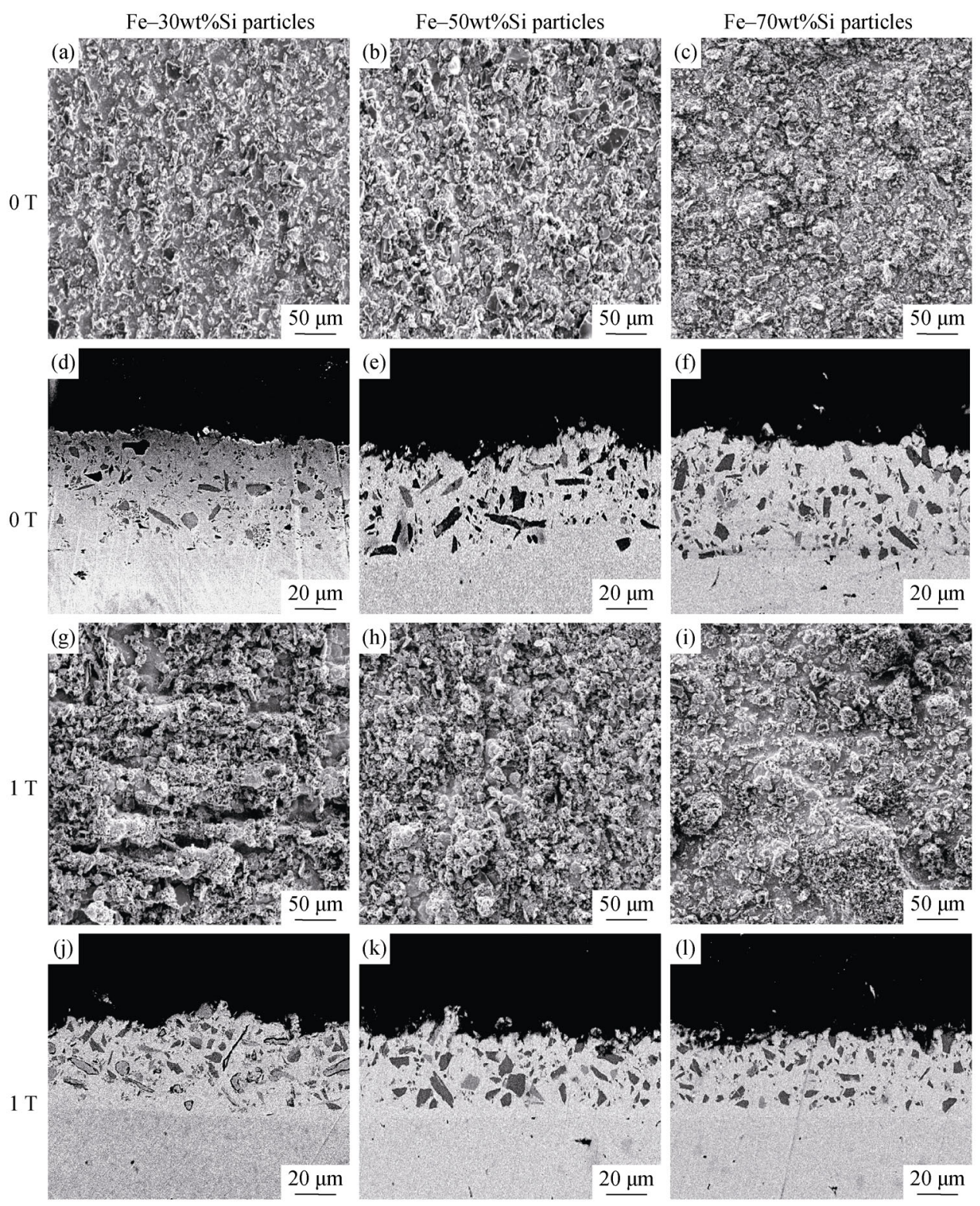

Fig. 10. SEM micrographs of the surface morphology of the coatings and the corresponding cross-sections for Fe-Si particles in the aclinic electrode system in the absence $((a-c)$ and $(d-f))$ and presence of a 1-T magnetic field $((g-i)$ and $(j-l))$. 


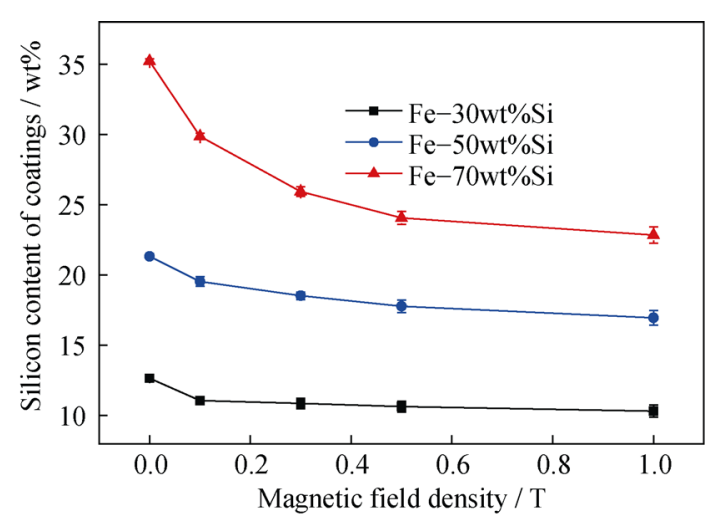

Fig. 11. Silicon content of the coatings in the case of an aclinic electrode system at a current density of $2 \mathrm{~A} \cdot \mathrm{dm}^{-2}$ in a perpendicular magnetic field.

3.2.4. Discussion of the experimental results obtained using a perpendicular magnetic field

According to Eq. (2), the Lorentz force reaches a maximum when the magnetic field is perpendicular to the current. As a consequence, an parallel flow in front of the cathode surface will be induced by the Lorentz force if the MFD is
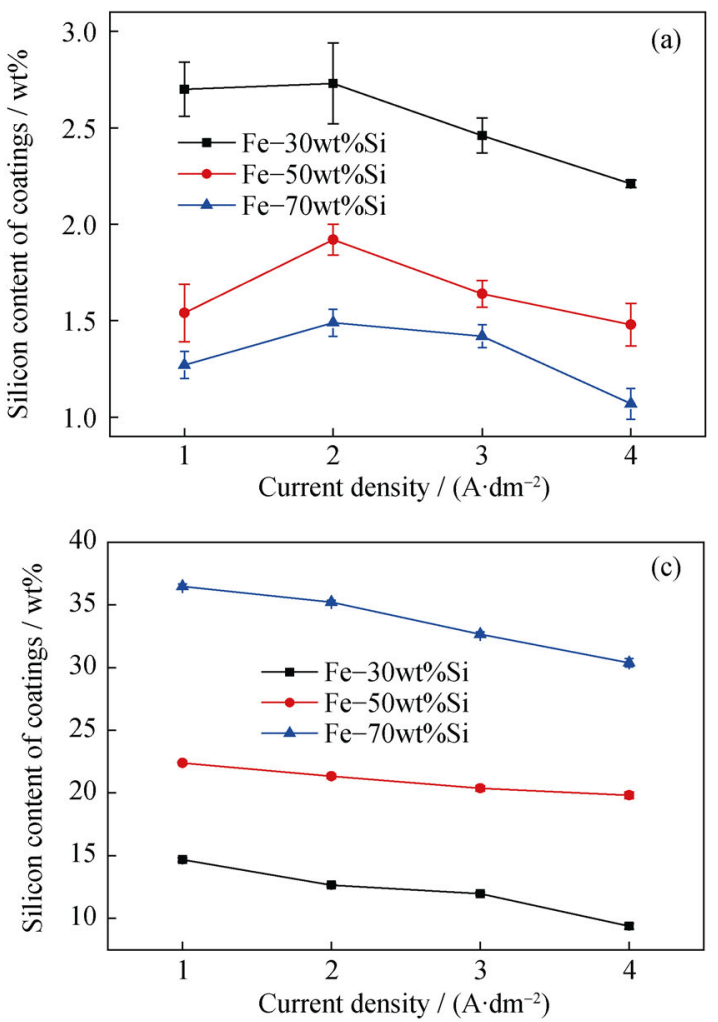

sufficiently high during the electrodeposition process [23] (Fig. 13), which can bring the enriched electrolyte to the concentration boundary layer and therefore locally improve the mass transfer. Thus, the MHD flow can improve the contact chance between a particle and the cathode surface and facilitate the particles being engulfed by the growing metal. The silicon content of coatings for the Fe-50wt $\% \mathrm{Si}$ and $\mathrm{Fe}-70 \mathrm{wt} \% \mathrm{Si}$ particles increased linearly with increasing MFD in the vertical electrode system. However, as with a parallel magnetic field, the particle content of the coatings in the case of the $\mathrm{Fe}-30 \mathrm{wt} \% \mathrm{Si}$ particles also decreased when the MFD was greater than $0.1 \mathrm{~T}$ because of their high susceptibility. Long et al. [21] reported that a perpendicular magnetic field only slightly promoted the co-deposition of weak diamagnetic Si particles, where the silicon content of their coatings only increased from $1.24 \mathrm{wt} \%$ in the absence of a magnetic field to $3.94 \mathrm{wt} \%$ in the presence of a $1-\mathrm{T}$ magnetic field. Therefore, we deduced that an appropriate strength of susceptibility of the Fe-Si particles can promote their incorporation into the coatings.
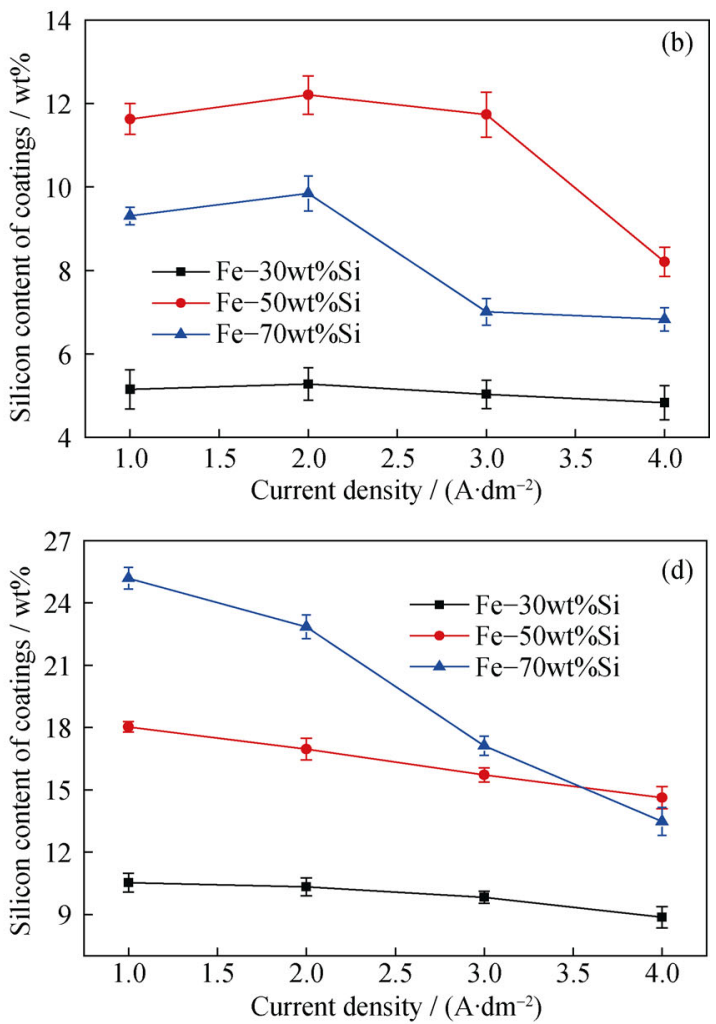

Fig. 12. Effects of current density on the silicon content of the coatings for the vertical electrode system: (a) $0 \mathrm{~T}$ and (b) 1T; and for the aclinic electrode system: (c) 0 T and (d) 1 T.

In the absence of a magnetic field, a huge number of particles reached the cathode surface under gravity in the aclinic electrode system, and a large portion of the particles were incorporated into the coatings. After a perpendicular magnetic field was imposed, a scouring effect in front of the cathode surface was induced by the Lorentz force. With increasing MFD, the scouring action became intense and carried some particles from the cathode surface back to the so- 
lution, which was disadvantageous for the co-deposition of $\mathrm{Fe}-\mathrm{Si}$ particles, and led to a decrease in silicon content of the coatings. Long et al. [21] observed that the silicon content of the coatings sharply decreased from $37.94 \mathrm{wt} \%$ at $0 \mathrm{~T}$ to $2.84 \mathrm{wt} \%$ at $1 \mathrm{~T}$. However, the iron cathodes had a strong $\boldsymbol{F}_{\nabla B}$ to the Fe-Si particles with a low silicon content, which can retard the movement of the Fe-Si particles on the cathode surface. For Fe-Si particles with a high silicon content, the $\boldsymbol{F}_{\nabla B}$ was small and the electrolyte flow easily carried the particles back to the solution, which led to the decrease in particle content. Furthermore, with increasing silicon content in the Fe-Si particles, their density significantly decreases (Table 3 ). Thus, they were more easily carried away from the cathode surface under the same intensity of MHD flow. As a result, a greater fluctuation of the silicon content in the coatings was induced.
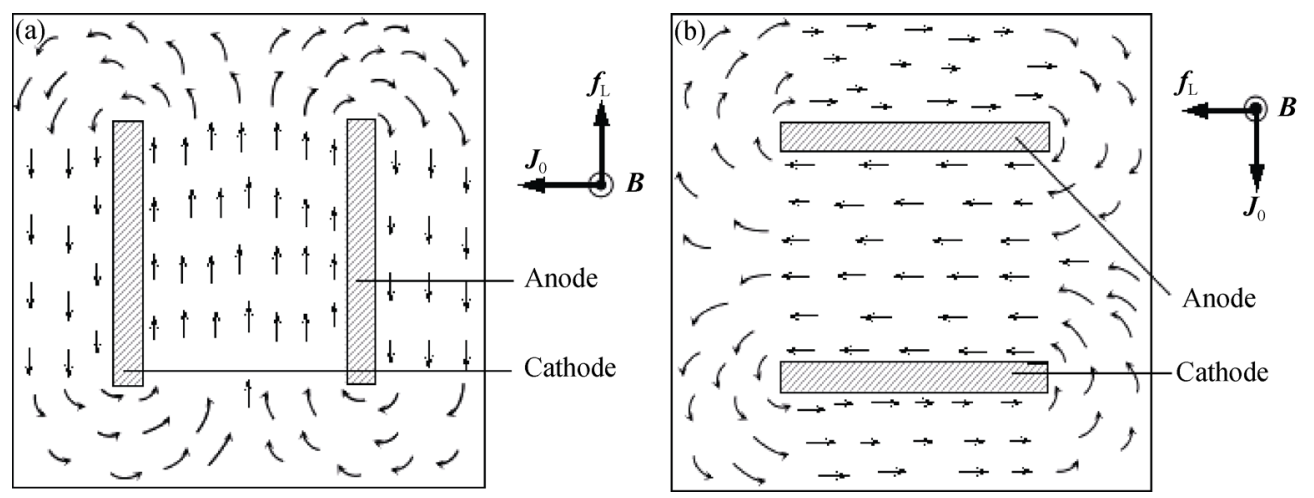

Fig. 13. Schematic illustration of MHD flow acting on the vertical electrode system (a) and the aclinic electrode system (b) in a perpendicular magnetic field.

Table 3. Density of $\mathrm{Fe}-\mathrm{Si}$ particles

\begin{tabular}{ccccc}
\hline Silicon content in particle $/ \mathrm{wt} \%$ & 30 & 50 & 70 & 100 \\
\hline Density of particles $/\left(\mathrm{g} \cdot \mathrm{cm}^{-3}\right)$ & 6.25 & 4.72 & 3.34 & 2.33 \\
\hline
\end{tabular}

Furthermore, according to Eq. (2), the current density makes a similar contribution of the magnetic field to the Lorentz force and can affect the co-deposition of particles. From Fig. 12(a), we deduced that the transfer rate of particles was faster than the growth rate of the metal when the current density was less than $2 \mathrm{~A} \cdot \mathrm{dm}^{-2}$, whereas the relationship between the transfer rate of the particles and the growth rate of the metal was reversed for the vertical-electrode plating when the current density was greater than $2 \mathrm{~A} \cdot \mathrm{dm}^{-2}$. In the absence of a magnetic field, the particles that adsorbed cations moved directly to the cathode under the effect of gravitational force and electric force and were engulfed by the growing metal. Meanwhile, with increasing current density, the polarization increased and the electrodeposition process was accompanied by intensive hydrogen evolution, which provided additional agitation in the near-electrode layer. Excessive agitation should decrease the particle content because the particles were ejected by the turbulent flow from the electrode surface before being incorporated. After a 1-T constant perpendicular magnetic field was applied, the field gradient $(\nabla \boldsymbol{B})$ remained constant when the current density was altered. The MHD effect caused by the Lorentz force and the turbulent flow caused by the evolution of hydrogen increased linearly with increasing current density, which led to the decreased silicon content of the coatings in the aclinic electrode system. However, in the case of the vertical electrode system, the particle concentration on the cathode surface was relatively low. When the strength of the electrolyte flow was weak, the electrolyte flow promoted the mass transport and led to the increase in particle content with increasing current density. However, when the current density was further increased, the electrolyte flow became more intense, and a scouring action was induced on the cathode surface, which resulted in a decrease in the silicon content of the coatings.

\subsection{Effects of magnetic field on cathode current effi- ciency}

Fig. 14 shows the cathode current efficiency in the absence and presence of a magnetic field. Fig. 14(a) indicates that the current efficiency significantly increased with increasing current density in the absence of a magnetic field. However, after an external magnetic field was imposed, the current efficiency decreased considerably with increasing MFD. At the same time, the current efficiency in the perpendicular magnetic field was lower than that in the parallel magnetic field when the vertical electrode system was used. Furthermore, the vertical electrode system had a lower current efficiency compared to that of the aclinic electrode system in the same perpendicular magnetic field (Fig. 14(b)). 

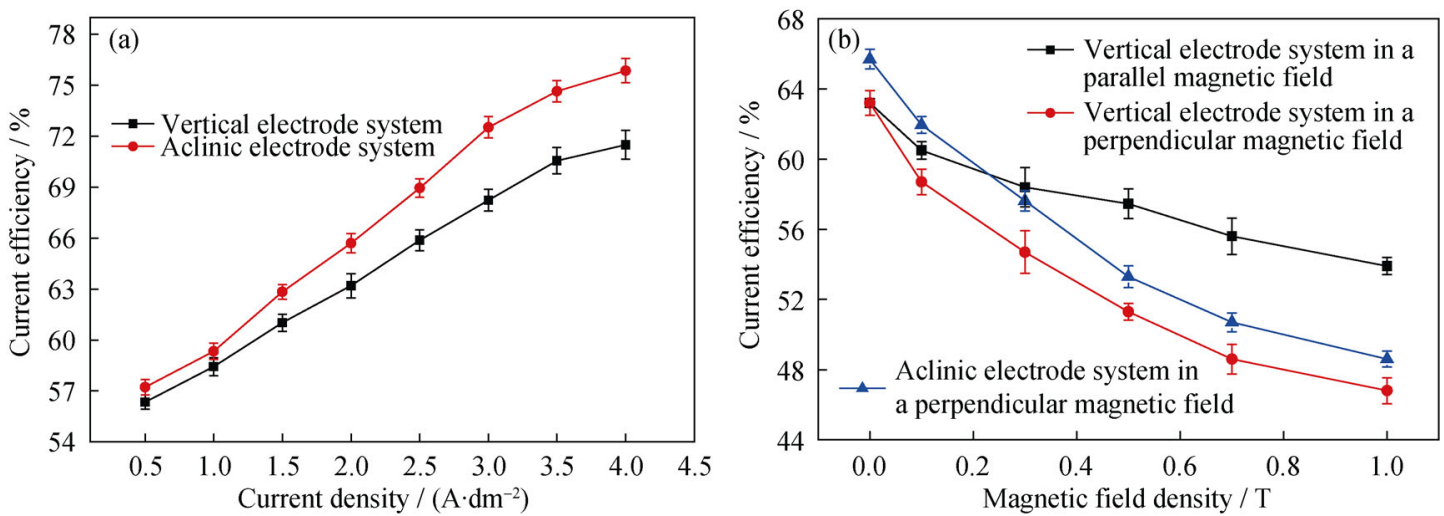

Fig. 14. Cathode current efficiency in the absence of a magnetic field under different current densities (a) and under different magnetic field densities at $2 \mathrm{~A} \cdot \mathrm{dm}^{-2}$ (b).

In the absence of a magnetic field, the dependence of the current efficiency on the current density is explained by an increase in the $\mathrm{pH}$ value near the cathode surface [24]. With increasing current density, the $\mathrm{pH}$ value increased sharply because of the consumption of $\mathrm{H}^{+}$ions. Because the equilibrium potential of the hydrogen evolution reaction shifted in the negative direction, the proportion of the iron electrodeposition current increased [25]. After a magnetic field was imposed, the MHD effect induced by the Lorentz force enhanced mass transport near the iron electrode. The convection reduced the thickness of the diffusion layer and resulted in an enhancement of hydrogen evolution. These results indicate that the iron electrodeposition reaction is mainly controlled by electron transfer in 0-1 T magnetic fields. Meanwhile, the upward turbulent flow induced by hydrogen evolution and natural convection in the vertical electrode system should be more intense than in the aclinic electrode system [21]. Thus, the current efficiency in the perpendicular magnetic field was lower than that in the parallel magnetic field, and the vertical electrode system exhibited a relatively lower current efficiency than the aclinic electrode system in the same perpendicular magnetic field. Low current efficiency can decrease the coating thickness, whereas high particle content in the composite coatings can increase the coating thickness. As a result, the coating thickness increased in the vertical electrode system and decreased in the aclinic electrode system. At the same time, the evolution of hydrogen, the micro-MHD effect, and a large number of particles in the coatings may have led to microcracks between the coating and the substrate when in the presence of a parallel magnetic field.

\section{Conclusions}

In such a sulfate-chloride plating bath, the electrodeposi- tion of $\mathrm{Fe}-\mathrm{Si}$ composite coatings was conducted in a magnetic field at $30^{\circ} \mathrm{C}$. The surface morphology and the silicon content of the coatings were investigated in the presence and the absence of a magnetic field. The following are the salient conclusions of the present study.

(1) When a low parallel magnetic field was imposed, numerous needle-like structures appeared on the coating surface; however, with increasing MFD, the needle-like structures weakened and were transformed into dome-shaped structures.

(2) Compared to results obtained in the absence of a magnetic field, those obtained under an applied external magnetic field significantly indicated significant promotion of the co-deposition process of $\mathrm{Fe}-\mathrm{Si}$ particles when the vertical electrode system was used, irrespective of the direction between the magnetic field and the current. In contrast, in the case of the aclinic electrode system, the opposite trend was observed.

(3) In the aclinic electrode system, for the particles with a higher silicon content, a decrease in silicon content of the coatings was more pronounced when the MFD was increased.

(4) The cathode current efficiency for iron electrodeposition in a magnetic field was considerably diminished. The current efficiency in a perpendicular magnetic field was lower than that in a parallel magnetic field, and the vertical electrode system exhibited a lower current efficiency than the aclinic electrode system. This lower current efficiency is mainly attributed to the mass transport induced by the MHD effect, hydrogen evolution, and natural convection.

\section{Acknowledgements}

This study was financially supported by the National Natural Science Foundation of China (No. 51034010) and 
the Science and Technology Commission of Shanghai $\mathrm{Mu}-$ nicipality (No. 13JC1402500).

\section{References}

[1] B.H. Park, B.S. Kang, S.D. Bu, T.W. Noh, J. Lee, and W. Jo, Lanthanum-substituted bismuth titanate for use in non-volatile memories, Nature, 401(1999), No. 6754, p. 682.

[2] T. Ros, Y. Houbaert, O. Fischer, and J. Schneider, Thermomechanical processing of high Si-steel (up to $6.3 \% \mathrm{Si}$ ), IEEE Trans. Magn., 37(2001), No. 4, p. 2321.

[3] F. Fiorillo, Advances in Fe-Si properties and their interpretation, J. Magn. Magn. Mater., 157-158(1996), p. 428.

[4] H.D. Fu, Z.H. Zhang, H.J. Pan, Y.K. Mo, and J.X. Xie, Warm/cold rolling processes for producing $\mathrm{Fe}-6.5 \mathrm{wt} \% \mathrm{Si}$ electrical steel with columnar grains, Int. J. Miner. Metall. Mater., 20(2013), p. 535.

[5] P.W. Zhou, Y.B. Zhong, H. Wang, Q. Long, F. Li, Z.Q. Sun, L.C. Dong, and L.J. Fan, Effects of parallel magnetic field on electrocodeposition behavior of Fe/nano-Si particles composite electroplating, Appl. Surf. Sci., 282(2013), p. 624.

[6] Y.J. Pan, H. Zhang, and X.J. Wu, Study on composite electroplating technology of iron with powder of silicon or ferrosilicon, Plat. Finish., 26(2004), No. 6, p. 13.

[7] S. Mohan, G. Saravanan, and A. Bund, Role of magnetic forces in pulse electrochemical deposition of Ni-nano $\mathrm{Al}_{2} \mathrm{O}_{3}$ composites, Electrochim. Acta, 64(2012), p. 94.

[8] A. Bund, A. Ispas, and G. Mutschke, Magnetic field effects on electrochemical metal depositions, Sci. Technol. Adv. Mater., 9(2008), No. 2, art. No. 024208.

[9] K. Tschulik, J.A. Koza, M. Uhlemann, A. Gebert, and L. Schultz, Effects of well-defined magnetic field gradients on the electrodeposition of copper and bismuth, Electrochem. Commun., 11(2009), No. 11, p. 2241.

[10] K. Tschulik, R. Sueptitz, J. Koza, M. Uhlemann, G. Mutschke, T. Weier, A. Gebert, and L. Schultz, Studies on the patterning effect of copper deposits in magnetic gradient fields, Electrochim. Acta, 56(2010), No. 1, p. 297.

[11] C. Wang, Y.B. Zhong, J. Wang, Z.Q. Wang, W.L. Ren, Z.S. Lei, and Z.M. Ren, Effect of magnetic field on electroplating $\mathrm{Ni} /$ nano- $\mathrm{Al}_{2} \mathrm{O}_{3}$ composite coating, J. Electroanal. Chem., 630(2009), p. 42.

[12] Q.Y. Feng, T.J. Li, Z.T. Zhang, J. Zhang, M. Liu, and J.Z. Jin, Preparation of nanostructured Ni/A12O3 composite coatings in high magnetic field, Surf. Coat. Technol., 201(2007), No. 14, p. 6247.
[13] F. Hu, K.C. Chan, and N.S. Qu, Effect of magnetic field on electrocodeposition behavior of Ni-SiC composites, J. Solid State Electrochem., 11(2007), No. 2, p. 267.

[14] T. Yamada and S. Asai, Distribution control of dispersed particles in a film fabricated by composite plating method using a high magnetic field, J. Jpn. Inst. Met., 69(2005), No. 2, p. 257.

[15] T. Yamada and S. Asai, Development of a new composite plating method orienting dispersed materials by use of a high magnetic field, J. Jpn. Inst. Met., 65(2001), No. 10, p. 910.

[16] F. Jiao, N.S. Qu, Z.W. Zhu, and X.L. Li, Preparation of nano-barium ferrite/CoNi alloy magnetic coating by composite electrodeposition, Mater. Mech. Eng., 33(2009), No. 12, p. 5.

[17] G. Hinds, J.M.D. Coey, and M.E.G. Lyons, Influence of magnetic forces on electrochemical mass transport, Electrochem. Commun., 3(2001), No. 5, p. 215.

[18] R. Peipmann, J. Thomas, and A. Bund, Electrocodeposition of nickel-alumina nanocomposite films under the influence of static magnetic fields, Electrochim. Acta, 52(2007), No. 19, p. 5808.

[19] A. Bund, S. Koehler, H.H. Kuehnlein, and W. Plieth, Magnetic field effects in electrochemical reactions, Electrochim. Acta, 49(2003), No. 1, p. 147.

[20] P.W. Zhou, Y.B. Zhong, H. Wang, L.J. Fan, L.C. Dong, F. Li, Q. Long, and T.X. Zheng, Behavior of Fe/nano-Si particles composite electrodeposition with a vertical electrode system in a static parallel magnetic field, Electrochim. Acta, 111(2013), p. 126.

[21] Q. Long, Y.B. Zhong, F. Li, C.M. Liu, J.F. Zhou, L.J. Fan, and M.J. Li, Effect of static magnetic field on the morphology and Si content of Fe-Si composite coating, Acta Metall. Sin., 49(2013), No. 10, p. 1201.

[22] C. Wang, Y.B. Zhong, W.L. Ren, Z.S. Lei, Z.M. Ren, J. Jia, and A.R. Jiang, Effects of parallel magnetic field on electrocodeposition behavior of $\mathrm{Ni} /$ nanoparticle composite electroplating, Appl. Surf. Sci., 254(2008), No. 18, p. 5649.

[23] A. Hovestad and L.J.J. Janssen, Electrochemical codeposition of inert particles in a metallic matrix, J. Appl. Electrochem., 25(1995), No. 6, p. 519.

[24] F. Hilbert, Y. Miyoshi, G. Eichkorn, and W.J. Lorenz, Correlations between the kinetics of electrolytic dissolution and deposition of iron, J. Electrochem. Soc., 118(1971), No. 12, p. 1927.

[25] H. Matsushima, T. Nohira, I. Mogi, and Y. Ito, Effects of magnetic fields on iron electrodeposition, Surf. Coat. Technol., 179(2004), No. 2-3, p. 245. 